\title{
Rotaxanes as cages to control DNA binding, cytotoxicity and cellular uptake of a small molecule
}

Timothy Kench, ${ }^{1}$ Peter A. Summers, ${ }^{1}$ Marina K. Kuimova, ${ }^{1}$ James E. M. Lewis ${ }^{1 *}$ and Ramon Vilar $^{1 *}$

${ }^{1}$ Department of Chemistry, Imperial College London, White City Campus, London W12 0BZ

*Corresponding authors: james.lewis@imperial.ac.uk and r.vilar@imperial.ac.uk

\begin{abstract}
The efficacy of many drugs can be limited by undesirable properties such as poor aqueous solubility, low bioavailability, and "off-target" interactions in the body. To combat these deficiencies, various drug carriers have been investigated to enhance the pharmacological profile of therapeutic agents. Inspired by the high degree of spatiotemporal control afforded by photopharmacology, in this work we demonstrate the potential for using mechanical protection to 'cage' a DNA-targeting metallodrug within a photodegradable rotaxane. More specifically, we report the synthesis of rotaxanes which incorporate as a stoppering unit a

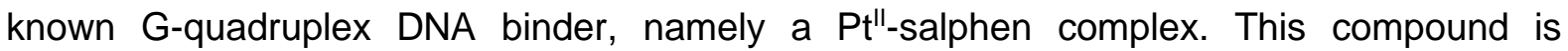
prevented from interacting with DNA when it is part of the mechanically interlocked assembly. The second rotaxane stopper was designed to be cleaved by either light or the activity of an esterase. In the presence of such stimuli, the rotaxane breaks apart, releasing the $\mathrm{Pt}^{\mathrm{I}}$-salphen complex and activating its ability to bind to DNA. We also show the mechanically interlocked system shows enhanced cell permeability and limited cytotoxicity within osteosarcoma cells compared to the free drug. Light activation, however, leads to a dramatic increase in cytotoxicity, concluded to arise from translocation to the nucleus and subsequent binding to DNA.
\end{abstract}

Keywords: Rotaxane, Quadruplex DNA, Platinum, Cellular Imaging, Photocaging 


\section{Introduction}

Mechanically interlocked molecules (MIMs) have begun to emerge as functional architectures for myriad applications. ${ }^{[1-5]}$ Following decades of intense research, there are now passive and active template synthetic methodologies for the preparation of highly complex interlocked molecular assemblies from simple reagents in minimal steps. ${ }^{[6-14]}$ This has elevated them from purely academic curiosities to realistic approaches for various applications. However, their use in a biological context remains underexplored. ${ }^{[15]}$ The few examples reported so far have utilised rotaxanes, one of the archetypal classes of MIMs consisting of a dumbbell-shaped axle encircled by a macrocycle. For example, polyrotaxane systems, with multiple macrocycles threaded onto polymeric axles, have been investigated as potential drug delivery vectors; ${ }^{[16-19]}$ generally, these are designed to act as drug reservoirs, with gradual cleavage of the stoppering units resulting in dethreading of macrocycle-drug conjugates over time. In these examples, the mechanical bond is employed simply as a non-covalent method of attaching drug payloads to the polymer. Rotaxanes have also been used as nanovalves for drug reservoirs through functionalisation of silica nanoparticles. ${ }^{[20]}$

An inherent characteristic of rotaxanes is that the macrocycle provides considerable steric bulk, shielding regions of the axle to an extent that would otherwise require unwieldy covalent units. This property has been applied in very few examples for biological applications. For example, rotaxanes have been used to deliver otherwise unstable or insoluble peptides or reactive fluorophores in cells, in which the payload is only released after rotaxane internalisation. ${ }^{[21-25]}$ Other examples include the selective delivery of a drug to cancer cells ${ }^{[26]}$ and a recent report wherein encirclement of a biocompatible 1,2,3-triazole linker by a macrocycle inhibited duplex formation of an unnatural DNA strand, supressing its ability to act as a primer for PCR amplification. ${ }^{[27]}$

Herein, we describe the use of rotaxanes to act as triggerable cages for DNA binders as well as to aid their controlled release inside cells. In particular, we have developed a system to 
selectively target G-quadruplex DNA (G4 DNA), a non-canonical DNA structure formed from guanine-rich sequences which has been implicated in various biological processes including telomeric maintenance, transcription, translation and replication. ${ }^{[28-30]}$ Additionally, they have emerged as highly attractive targets for anti-cancer therapeutics due to their prevalence in oncogene promoter regions and the telomere (the dysregulation of which is a key hallmark of cancer). ${ }^{[31-34]}$ Compelling evidence for the existence of G4s in vivo has emerged through a combination of bioinformatic studies, ${ }^{[35,36]}$ DNA sequencing, ${ }^{[37,38]}$ immunostaining in fixed cells ${ }^{[39,40]}$ and small molecule visualisation. ${ }^{[41,42]}$ There are currently only a handful of probes in which G4 interaction can be controlled through an external trigger. ${ }^{[43]}$ These systems, in which a ligand can be switched from an inactive to active state, display highly desirable properties and have been utilised to photo-control G4 binding and gene expression ${ }^{[4,45]}$ and in the design of hypoxia activated probes. ${ }^{[46]}$ Given the prevalence of G4s in many important biological processes, the increased control gained by such systems is enticing.

We have developed a series of [2]rotaxanes incorporating a square planar Pt"-salphen complex (a previously established G4 ligand) ${ }^{[47,48]}$ as a stoppering unit. Herein we show that within the interlocked structure the G4 DNA binding of the active Pt" complex is almost entirely inhibited due to the steric bulk of the macrocycle. Through the inclusion of immolating stoppering units, activated through either enzymatic cleavage or light irradiation, the macrocycle can be induced to dethread, resulting in a switching-on of the G4 binding properties of the ligand. This work paves the way for a new approach to control the G4 DNA targeting properties of ligands via non-invasive activation with both temporal and spatial control.

\section{Results and discussion}

Rotaxane design, synthesis and characterisation. We designed our [2]rotaxane cages to release a G4 binding ligand through a sequential two-stage cleavage process (Figure 1a). We envisaged that the first stage would provide the primary activation trigger, whilst the second 
would be used to remove any remaining steric bulk which might inhibit G4 binding. In order to demonstrate the efficacy and ease of use of this approach, we utilised Cu'-mediated azidealkyne cycloaddition (CuAAC) active metal template synthesis for which a wide range of suitable components have previously been reported. ${ }^{[49-51]}$

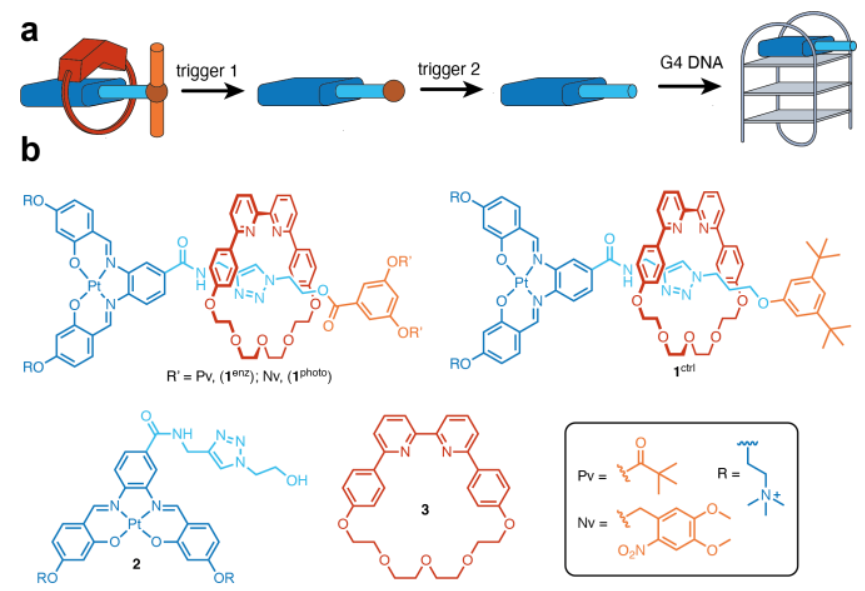

Figure 1 - Rotaxanes as triggerable cages. a) Schematic showing two-stage sequential activation mechanism in which G4 binding is initially blocked via the presence of a macrocycle and then subsequently activated allowing for G4 DNA stabilisation. b) Rotaxane compounds triggered by enzymatic activity $\left(\mathbf{1}^{\text {enz }}\right)$ or photo-activation (1 $\left.{ }^{\text {photo }}\right)$ and their non cleavable analogue (1 $\left.{ }^{\text {trl }}\right)$ alongside 'uncaged' Pt"-salphen $\mathbf{2}$ and bipyridine Cu'-binding macrocycle $\mathbf{3}$.

Rotaxanes $\mathbf{1}^{\text {enz }}, \mathbf{1}^{\text {photo }}$ and $\mathbf{1}^{\text {ctrl }}$ were synthesised from an alkyne-functionalised $\mathrm{Pt}$-salphen complex (the G4 binder), the respective azide functionalised stopper groups and the bipyridine-based macrocycle 3 (Figure 1b). ${ }^{[52]}$ To demonstrate two orthogonal primary methods of activation, we synthesised an esterase-activated pivalic ester rotaxane ( $\left.\mathbf{1}^{\mathrm{enz}}\right)$ and a photolabile nitroveratyl rotaxane $\left(\mathbf{1}^{\text {photo }}\right)$ in which the protecting groups had sufficient size to prevent dethreading of the interlocked assembly until they were cleaved. In both cases the secondary trigger was enzymatic ester hydrolysis, achieved through the inclusion of an ester bond between the triazole and stopper group core. The sequential order of each cleavage step was based on previous reports which demonstrated that the proximity of a macrocycle to an ester bond could inhibit esterase activity. ${ }^{[26]}$ In addition, a non-cleavable control rotaxane ( $\left.\mathbf{1}^{\text {ctrl }}\right)$ was synthesised for comparison. 
Whilst this approach has the potential to include any alkyne functionalised G4 binder, we chose a Pt"-salphen complex as a proof-of-principle since this type of square-planar compound is highly effective at stabilising G4s and has suitable dimensions to be used as a rotaxane stopper group. Importantly, Pt"-salphen complexes also display 'switch-on' emission under certain conditions (including DNA binding) ${ }^{[47]}$ and therefore its interactions with DNA in cellulo can be monitored by fluorescence microscopy. Two quaternary ammonium side chains were incorporated to enhance G4 stabilisation through interaction with the DNA phosphate backbone in addition to providing water solubility. In order to confirm that the $\mathrm{Pt}^{\mathrm{Il}}$-salphen resulting from 'uncaging' could still stabilise G4 DNA, compound 2 was synthesised via CuAAC reaction. In all cases, purity was confirmed by ${ }^{1} \mathrm{H}$ NMR spectroscopy, high resolution mass spectrometry and LCMS and, where suitable, 2D NMR was used as further evidence that the complex contained interlocked components (see Supporting Information for full details).

The ${ }^{1} \mathrm{H}$ NMR spectrum of rotaxane $1^{\text {enz }}$ as a representative example is shown in Figure 1a; significant upfield shifts can be observed in the aromatic region for macrocycle $\mathbf{3}$ and for the Pt"-salphen moiety. In addition, a further divergence in the chemical shifts between each side of the salphen ligand can be seen due to the increased shielding from the presence of the macrocycle which is off-centre. A remarkably large perturbation of almost $4 \mathrm{ppm}$ is seen for the amide proton $\left(\mathrm{H}_{\mathrm{O}}\right.$ in Figure $2 \mathrm{a}$ ), indicative of hydrogen bonding between the amide and bipyridine units, optimally positioning the macrocycle near the $\mathrm{Pt}^{\mathrm{I}}$-salphen moiety. Furthermore, 2D NOESY cross coupling peaks are seen between axle and macrocycle components (Figure S17). Across all rotaxanes the salphen and macrocycle chemical shifts are generally conserved, indicating that the macrocycle is similarly positioned in all cases (Figure 2b). 


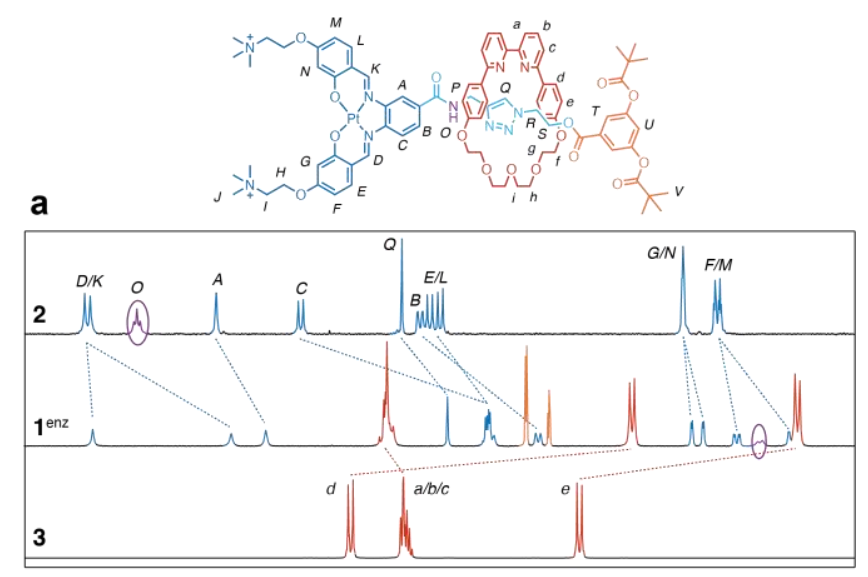

\begin{tabular}{llllllllllllllllllllll}
\hline $9^{\prime} \cdot 6$ & 9.4 & 9.2 & 9.0 & 8.8 & 8.6 & 8.4 & 8.2 & 8.0 & 7.8 & 7.6 & 7.4 & 7.2 & 7.0 & 6.8 & 6.6 & 6.4 & 6.2 & 6.0
\end{tabular} b

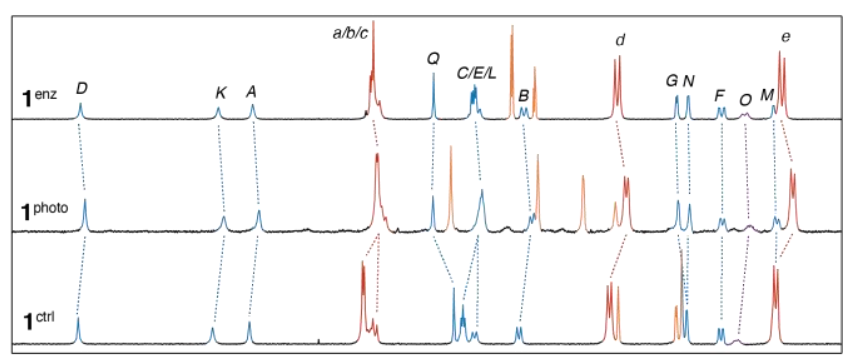

\begin{tabular}{llllllllllllllllllllll}
\hline 9.6 & 9.4 & 9.2 & 9.0 & 8.8 & 8.6 & 8.4 & 8.2 & 8.0 & 7.8 & 7.6 & 7.4 & 7.2 & 7.0 & 6.8 & 6.6 & 6.4 & 6.2 & 6.0 \\
Chemical shift (ppm)
\end{tabular}

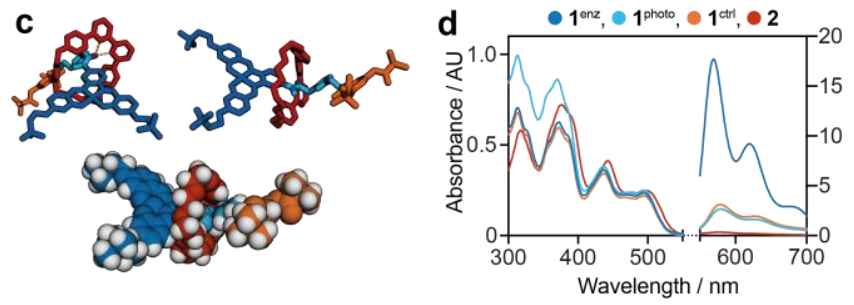

Figure 2 - Rotaxane characterisation. a) Section of the ${ }^{1} \mathrm{H}$ NMR (DMSO-d6, $400 \mathrm{MHz}$ ) spectrum of Pt"salphen complex 2 (blue), rotaxane $\mathbf{1}^{\text {enz }}$ and macrocycle $\mathbf{3}$ (red) (top to bottom) with additional peaks corresponding to the axle component (orange) highlighted in the rotaxane ${ }^{1} \mathrm{H}$ NMR spectrum. b) Stacked ${ }^{1} \mathrm{H}$ NMR spectra of rotaxanes $\mathbf{1}^{\mathrm{enz}}, \mathbf{1}^{\text {photo }}$ and $\mathbf{1}^{\text {ctrl }}$. c) Energy minimised structure of rotaxane $\mathbf{1}^{\text {enz }}$ alongside a space-filled model. Strong hydrogen bonds (2.4 and $\left.2.5 \AA\right)$ can be seen between the amide proton on the axle and the bipyridine nitrogen and are highlighted in yellow. $\mathbf{d}$ ) Absorbance (left) and emission (right) spectra of rotaxanes $1^{\mathrm{enz}}, \mathbf{1}^{\text {photo }}, \mathbf{1}^{\mathrm{ctrl}}$ and Pt"l-salphen 2 (all at $50 \mu \mathrm{M}$ in water), showing similar absorptivity but significantly different emission intensities $\left(\lambda_{\mathrm{ex}}=440 \mathrm{~nm}\right)$.

In order to confirm that the preferred macrocycle position was over the amide bond we carried out geometry optimisation of rotaxane $1^{\text {ctrl }}$ (as a representative example) using Density Functional Theory (DFT). The structure was minimised using a B3LYP functional with 6-31g and LANL2DZ basis sets and water as the solvent. As can be seen from Figure $2 \mathrm{c}$, the structure obtained matched our hypothesis: the macrocycle sits directly above the amide bond with a bifurcated hydrogen bond between the axle's amide proton and bipyridine of the macrocycle (2.4 and $2.5 \AA$ ). The position of the macrocycle is off-centre with hydrogen bonding 
displayed between the imine (from the salphen) and an $\mathrm{O}$ atom from the macrocycle. This is consistent with the NMR data, which showed a significant divergence in chemical shifts for the imine protons $D$ and $K$ and a large upfield shift for the amide proton $\mathrm{H}_{O}$. From the space-filled model it is evident that macrocycle effectively blocks access to a large portion of the aromatic surface of the salphen ligand.

Next, the absorbance spectra of $\mathbf{1}^{\text {enz }}, \mathbf{1}^{\text {photo }}, \mathbf{1}^{\text {ctrl }}$ and 2 were recorded; as expected, in the region corresponding to the $\mathrm{Pt}^{\mathrm{I}}$-salphen complex there was little deviation amongst these four compounds (Figure 2d). However, whilst all compounds displayed the same emission profile with a characteristic primary peak at $590 \mathrm{~nm}$, large differences were observed in intensities. Unhindered Pt"-salphens such as 2 normally undergo aggregation-induced quenching in aqueous media through $\pi-\pi$ stacking; however, it is evident that the presence of the macrocycle partly blocks this process, switching emission back on. Interestingly, a much higher emission was seen for $\mathbf{1}^{\text {enz }}$ as compared to $\mathbf{1}^{\text {photo }}$ and $\mathbf{1}^{\text {ctrl }}$. Given the similar ${ }^{1} \mathrm{H}$ NMR data for the three rotaxanes, it is likely that the differences in hydrophobicity and size of the second stopper group cause differences in aggregation in aqueous media.

DNA binding studies. The DNA binding properties of the three rotaxanes $\left(\mathbf{1}^{\text {enz }}, \mathbf{1}^{\text {photo }}, \mathbf{1}^{\text {ctrl }}\right)$ and 2 were investigated via biophysical assays. Emission titrations upon addition of increasing equivalents of DNA are shown in Figure 3. Three G4 structures, namely $\mathrm{HTelo}\left(\mathrm{Na}^{+}\right), \mathrm{HTelo}$ $\left(K^{+}\right)$and $c-M y c$, (i.e. parallel, hybrid and anti-parallel) as well as CT-DNA were tested. As can be seen in Figure 3a-d, all the rotaxanes showed virtually no switch-on effect, with no distinction between G4 and duplex DNA. In contrast, 2 was shown to be a highly selective G4 DNA binder and probe, with $\mathrm{K}_{\mathrm{a}}$ values in the $10^{6} \mathrm{M}^{-1}$ range and a slight preference for the HTelo $\left(\mathrm{Na}^{+}\right)$over HTelo $\left(\mathrm{K}^{+}\right)$and $c-\mathrm{Myc}\left(\mathrm{K}_{\mathrm{a}}=1.1 \pm 0.2 \times 10^{6} \mathrm{M}^{-1}\right.$ compared to $7.0 \pm 0.1 \times 10^{5}$ and $6.8 \pm 0.1 \times 10^{5} \mathrm{M}^{-1}$, respectively). Additionally, the probe showed ca. 500 -fold selectivity for $\mathrm{G} 4$ over CT-DNA $\left(\mathrm{K}_{\mathrm{a}}=1.8 \pm 0.1 \times 10^{3} \mathrm{M}^{-1}\right)$. Obtaining affinity constants for the rotaxanes with this method was not possible since the changes in emission were negligible. This indicates that 
rotaxane formation severely inhibits any DNA binding, with the macrocycle blocking access to the planar face of the $\mathrm{Pt}^{\prime \prime}$-salphen complex which in turn prevents any $\pi-\pi$ stacking interactions from occurring.
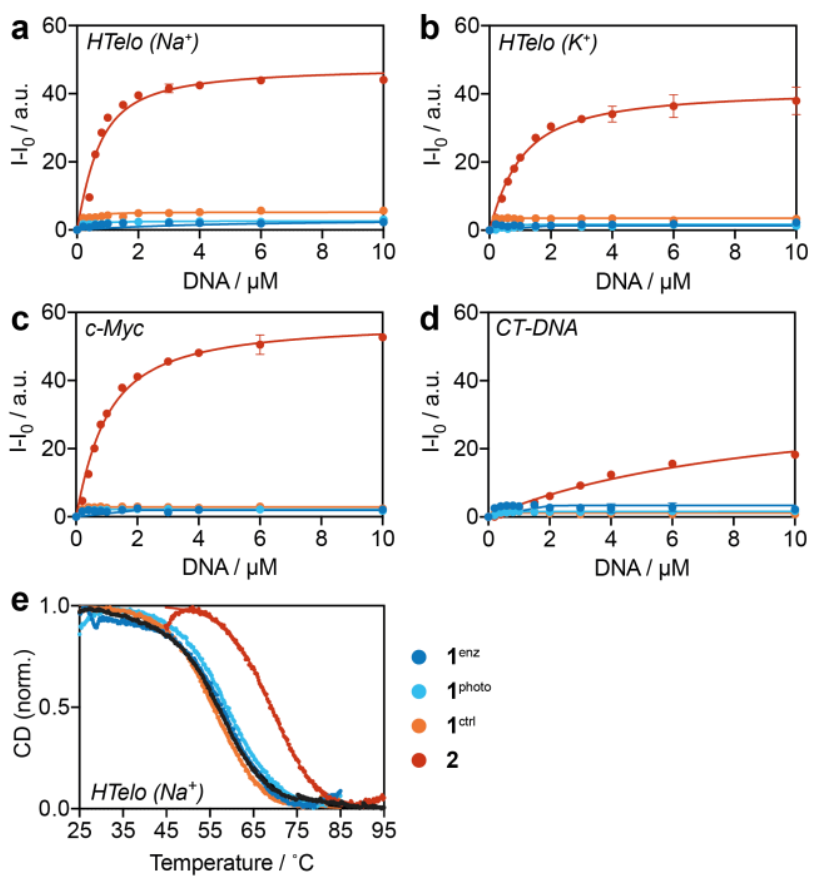

Figure 3 - DNA binding experiments. a-d) DNA titrations with rotaxanes $1^{\text {enz }}, \mathbf{1}^{\text {photo }}, \mathbf{1}^{\text {ctrl }}$ and $\mathrm{Pt}$-salphen 2 (all at $2 \mu \mathrm{M}$ ) with HTelo $\left(\mathrm{Na}^{+}\right)$, HTelo $\left(\mathrm{K}^{+}\right), \mathrm{c}-\mathrm{Myc}$ and $\mathrm{CT}$-DNA respectively. For $\mathrm{G} 4$ forming sequences, concentration is given per strand whilst for $C T$-DNA concentration is per base pair of DNA. $\lambda_{\mathrm{ex}}=440 \mathrm{~nm}, \lambda_{\mathrm{em}}=590 \mathrm{~nm}$. e) CD melting spectra of HTelo $\left(\mathrm{Na}^{+}\right)$(shown in black) $(5 \mu \mathrm{M})$ and HTelo $\left(\mathrm{Na}^{+}\right)+\mathbf{1}^{\text {enz }}, \mathbf{1}^{\text {photo }}, \mathbf{1}^{\text {ctrl }}$ and $2(10 \mu \mathrm{M})$.

Circular dichroism (CD) melting experiments were subsequently conducted in order to confirm the DNA binding properties of the rotaxanes and their components (Figure 3e). HTelo $\left(\mathrm{Na}^{+}\right)$ G4 DNA was selected for further testing as Pt"-salphen 2 had shown the largest $\mathrm{K}_{\mathrm{a}}$ values for this structure. As can be seen in Figure $3 e$, the three rotaxanes $\left(\mathbf{1}^{\text {enz }}, \mathbf{1}^{\text {photo }}\right.$ and $\left.\mathbf{1}^{\text {ctr }}\right)$ displayed little to no thermal stabilisation, whilst 2 showed good thermal stabilisation of HTelo $(12.1 \pm 0.1$ $\left.{ }^{\circ} \mathrm{C}\right)$. Furthermore, as this assay exclusively measures changes in DNA properties it provides clear evidence that DNA binding is indeed blocked when the Pt"-salphen is 'caged' in the rotaxane.

Stability and activation of rotaxanes. We next investigated whether the rotaxanes were stable in a biological environment and if their DNA binding properties could be successfully triggered by external stimuli. After confirming that the rotaxanes were stable in buffer (Figure 
S37), we incubated rotaxanes $1^{\text {enz }}, 1^{\text {photo }}$ and $1^{\text {ctrl }}$ in human serum at $37^{\circ} \mathrm{C}$ for 24 hours. At various timepoints samples were taken, treated and analysed by HPLC (for assignment of product peaks see Figure S38 and S39). Rotaxane $1^{\text {enz }}$ was designed to be activated through esterase-catalysed hydrolysis of the pivalic ester bonds, followed by hydrolysis of the aryl ester. This was confirmed experimentally; as shown in Figure 4a: over time rotaxane $1^{\text {enz }}$ disappeared while new peaks associated with dethreading of the macrocycle appeared. Under these conditions, pivalic ester hydrolysis occurred in a two-stage process in which one pivalic ester was cleaved first which removed enough steric bulk to allow for macrocycle dethreading. This was then followed by concurrent hydrolysis of the second pivalic ester and the aryl ester, which led to the formation of 2 . In contrast, neither $\mathbf{1}^{\text {photo }}$ nor $\mathbf{1}^{\text {ctrl }}$ (designed not to be cleaved by esterases) underwent any change upon incubation in human serum at $37^{\circ} \mathrm{C}$ for up to $24 \mathrm{~h}$ (Figure S40).

We sought to confirm the formation of the free $\mathrm{Pt}^{\text {HI}}$-salphen complex 2 from the cleavage of $\mathbf{1}^{\text {enz }}$ utilising porcine liver esterase (PLE) (Figure 4b). In this experiment, $\mathbf{1}^{\text {enz }}$ was incubated at $37^{\circ} \mathrm{C}$ in PBS buffer in the presence of excess PLE. At each timepoint a small sample was withdrawn, and the enzyme denatured before HPLC analysis. Hydrolysis of the pivalic ester bond was more rapid under these conditions which led to complete disappearance of the rotaxane peak within one hour with no intermediate single-pivalic ester product. Under these conditions a peak corresponding to 2 was observable and after 24 hours near complete conversion to the desired product was confirmed.

After showing that rotaxane $\mathbf{1}^{\text {photo }}$ was stable in human serum, we tested whether the photoactivated uncaging could occur. A solution of $1^{\text {photo }}$ in PBS buffer was irradiated using $365 \mathrm{~nm}$ light for a total of 1 hour (Figure 4c), during which small samples were removed at various timepoints. Similar to the serum stability experiment, a two-stage process took place in which one nitroveratyl group was cleaved first, which led to macrocycle dethreading, followed by cleavage of the second nitroveratyl group. Interestingly, a further reaction was also observed 
in which the aryl ester in the axle was hydrolysed. Full rotaxane breakdown occurred within 10 minutes.

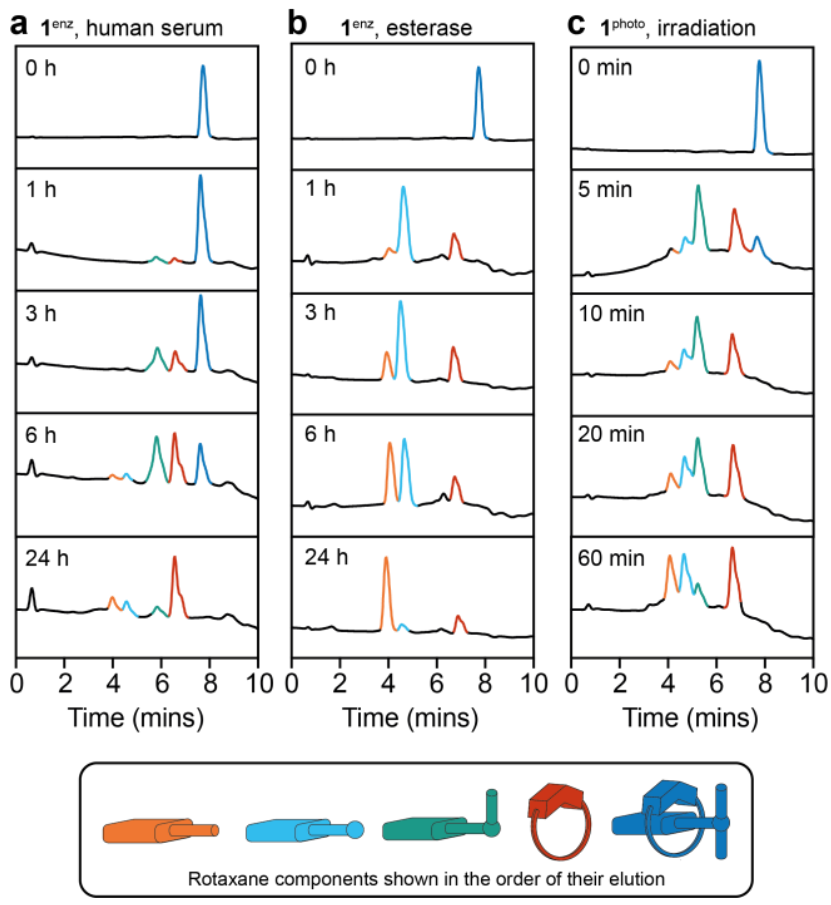

Figure 4 - A series of stability and activation experiments for $\mathbf{1}^{\text {enz }}$ and $\mathbf{1}^{\text {photo }}$. a) Stability of rotaxane $1^{\text {enz }}$ in human serum incubated at $37^{\circ} \mathrm{C}$ over 24 hours, followed by protein precipitation and HPLC analysis. b) Esterase activation of $\mathbf{1}^{\mathrm{enz}}$ carried out using porcine liver esterase (PLE) in PBS buffer at $37^{\circ} \mathrm{C}$ over 24 hours, followed by denaturing and HPLC analysis. c) Irradiation activation of $1^{\text {photo }}$ using $365 \mathrm{~nm}$ light over 1 hour.

In order to confirm that G4 DNA binding was restored after triggered release of $\mathbf{2}$, we carried out a series of titrations using a sample of rotaxane $1^{\text {enz }}$ which had been treated with PLE for 24 hours. The sample was directly diluted without any further steps and titrated against $c-M y c$, HTelo and CT-DNA, with a negative control with no PLE and a positive control including 2 with PLE. The results are summarised in Figure 5a-c; treatment of $1^{\text {enz }}$ with PLE led to excellent G4 stabilisation, nearly in line with the positive control ( $c-M y c: 1^{\mathrm{enz}}+\mathrm{PLE}, \mathrm{K}_{\mathrm{a}}=4.7 \pm 0.8 \times 10^{6} \mathrm{M}^{-}$ 1; 2, $\mathrm{K}_{\mathrm{a}}=2.4 \pm 0.3 \times 10^{6} \mathrm{M}^{-1} ;$ HTelo: $\mathbf{1}^{\mathrm{enz}}+\mathrm{PLE}, \mathrm{K}_{\mathrm{a}}=1.0 \pm 0.3 \times 10^{6} \mathrm{M}^{-1} ; \mathbf{2}, \mathrm{K}_{\mathrm{a}}=1.0 \pm 0.4 \times 10^{6} \mathrm{M}^{-}$ $\left.{ }^{1}\right)$. The slightly lower total fluorescence response is presumably due to incomplete conversion; however, the results clearly indicate that the system worked as desired. 

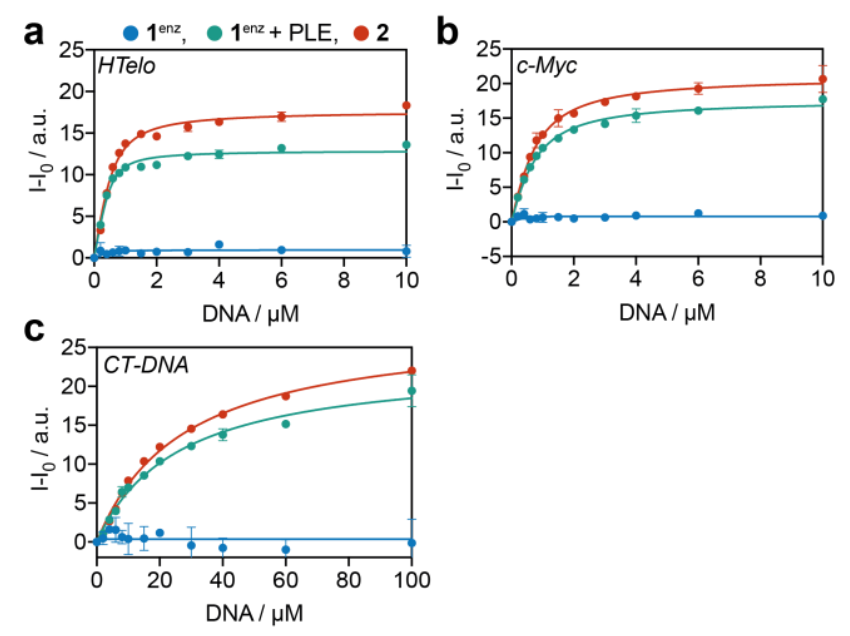

Figure 5 - Binding activation experiments in which rotaxane $1^{\mathrm{enz}}$ and salphen 2 were treated with 50 equivalents of PLE per $\mu \mathrm{mol}$ and incubated at $37^{\circ} \mathrm{C}$ in PBS for 24 hours, after which the solution was used for fluorescence titrations with a) Htelo G4 DNA, b) c-Myc G4 DNA and c) CT-DNA. $\lambda_{\mathrm{ex}}=440$ $\mathrm{nm}, \lambda_{\mathrm{em}}=590 \mathrm{~nm}$.

Cell viability and fluorescence microscopy. Having established the DNA binding properties of the compounds, we next studied their cellular permeability and cytotoxicity. Cell viability assays were carried out with U2OS osteosarcoma cells for the three rotaxanes and Pt"salphen complex 2 (Figure 6a-d). The cells were seeded for 24 hours, followed by compound addition and a further 24 hour incubation. In order to investigate the photo-cytotoxicity of $\mathbf{1}^{\text {photo }}$, an additional assay was run in which identical conditions were used except the cells were exposed to 20 minutes of $365 \mathrm{~nm}$ UV after 3 hours of compound incubation. Rotaxane $1^{\text {ctrl }}$ was also included in this photo-cytotoxicity assay in order to confirm that any potential effects were due to rotaxane activation and not the effect of UV irradiation on cells or reactive oxygen species generation from the platinum complex. Live cell fluorescence microscopy was used to confirm cellular uptake (Figure 6e-h).

Firstly, compound $\mathbf{2}$ was shown to cause no inhibition of cell growth (Figure 6a), which was surprising as other $\mathrm{Pt}^{\mathrm{H}}$-salphen complexes have been previously reported to be cytotoxic. Low cellular internalisation of $\mathbf{2}$ under these conditions was confirmed by fluorescence microscopy which is likely the reason for the low cytotoxicity (Figure 6e). In contrast, the three rotaxanes displayed varying cytotoxicity and were all shown to be cell permeable. Rotaxane $1^{\text {enz }}$ inhibited 
cell growth in a dose dependent manner, with an $\mathrm{IC}_{50}$ value of $24 \mu \mathrm{M}$ (Figure $6 \mathrm{~b}$ ) whereas $\mathbf{1}^{\text {photo }}$ was shown to be non-cytotoxic in the dark under these conditions (Figure $6 \mathrm{c}$ ) and $\mathbf{1}^{\text {ctrl }}$ (dark) also showed minimal inhibitory effects (Figure 6d). As the cellular internalisation of these compounds was confirmed (Figure 6f-h), the low cytotoxicity of the interlocked assemblies could be explained by the 'caging' of the $\mathrm{Pt}^{\prime \prime}$-salphen complex by rotaxanes. The increased cell growth inhibition caused by rotaxane $\mathbf{1}^{\text {enz }}$ compared with $\mathbf{1}^{\text {photo }}$ and $\mathbf{1}^{\text {ctrl }}$ is likely due to hydrolysis of the pivalic esters by endogenous esterases, causing release of a $\mathrm{Pt}^{\prime \prime}-$ salphen complex inside the cells. The differences in uptake between the rotaxanes and $\mathbf{2}$ is probably caused by the increased hydrophobicity of the secondary stopper groups and shows the importance of balancing both water solubility and cell permeability in such systems.

Exposure of rotaxane $\mathbf{1}^{\text {photo }}$ to UV irradiation led to a dramatic increase in cell growth inhibition at all tested concentrations, with an $\mathrm{IC}_{50}$ of $3.8 \mu \mathrm{M}$ and near complete cell death at a dose of $10 \mu \mathrm{M}$ (Figure $6 \mathrm{c}$ ). In contrast, the control rotaxane ( $\left.\mathbf{1}^{\mathrm{ctrl}}\right)$ displayed little to no increase in cytotoxicity upon irradiation. This suggests that the photo-activated uncaging mechanism is highly effective in a cellular environment, while the presence of the macrocycle inhibits the cytotoxic activity of the Pt"-salphen. Further cell viability assays were carried out to test whether the remaining rotaxane fragments (i.e. macrocycle 3 and 3,5-dihydroxybenzoic acid - stopper released upon disassemble) or the effect of UV irradiation could be causing cell death. Pleasingly, in all cases no decrease in cell viability was observed (Figure S43), demonstrating that the light triggered cytotoxic effect is due to the release of the Pt"-salphen complex.

Cellular images for the three rotaxane compounds showed punctate staining in all cases. For $1^{\text {photo }}$ the vesicle-like staining was highly prominent with virtually no background staining, unlike with $\mathbf{1}^{\mathrm{enz}}$, which included some general background staining. It is noticeable that under these conditions in live cells none of the rotaxanes localised in the nucleus. Additionally, 
rotaxanes $1^{\text {photo }}$ was tested for colocalisation with Lysotracker green but showed no overlap (Figure S44).

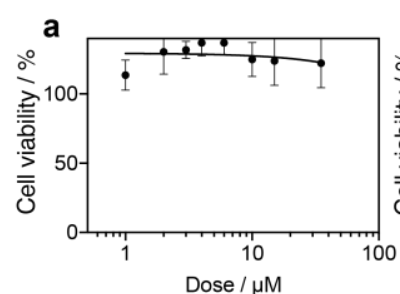

Live cell imaging
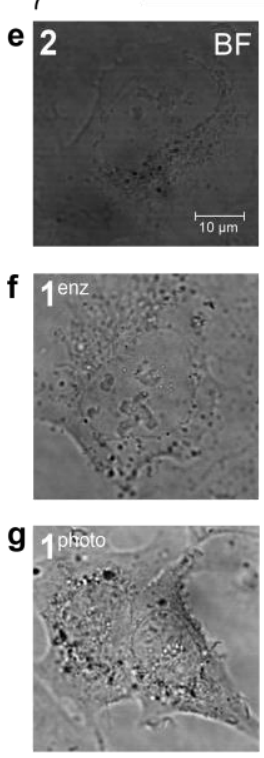

h
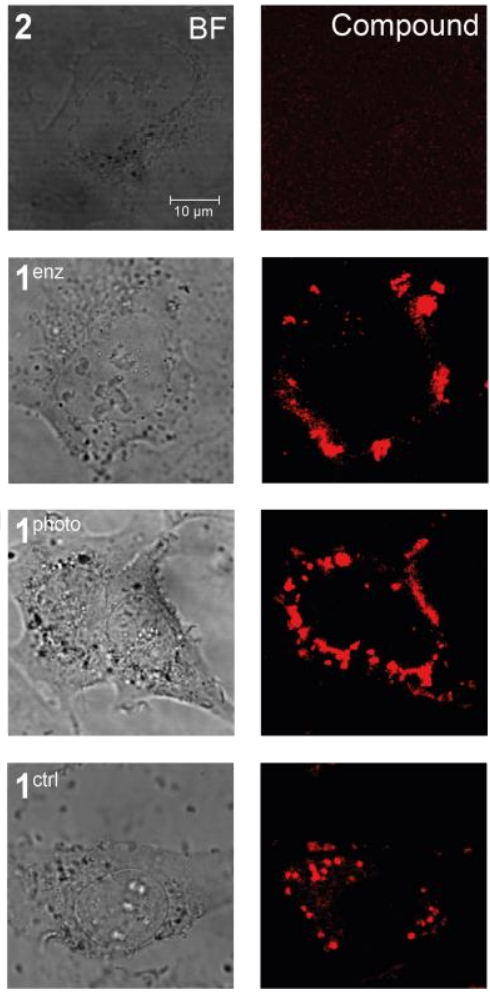
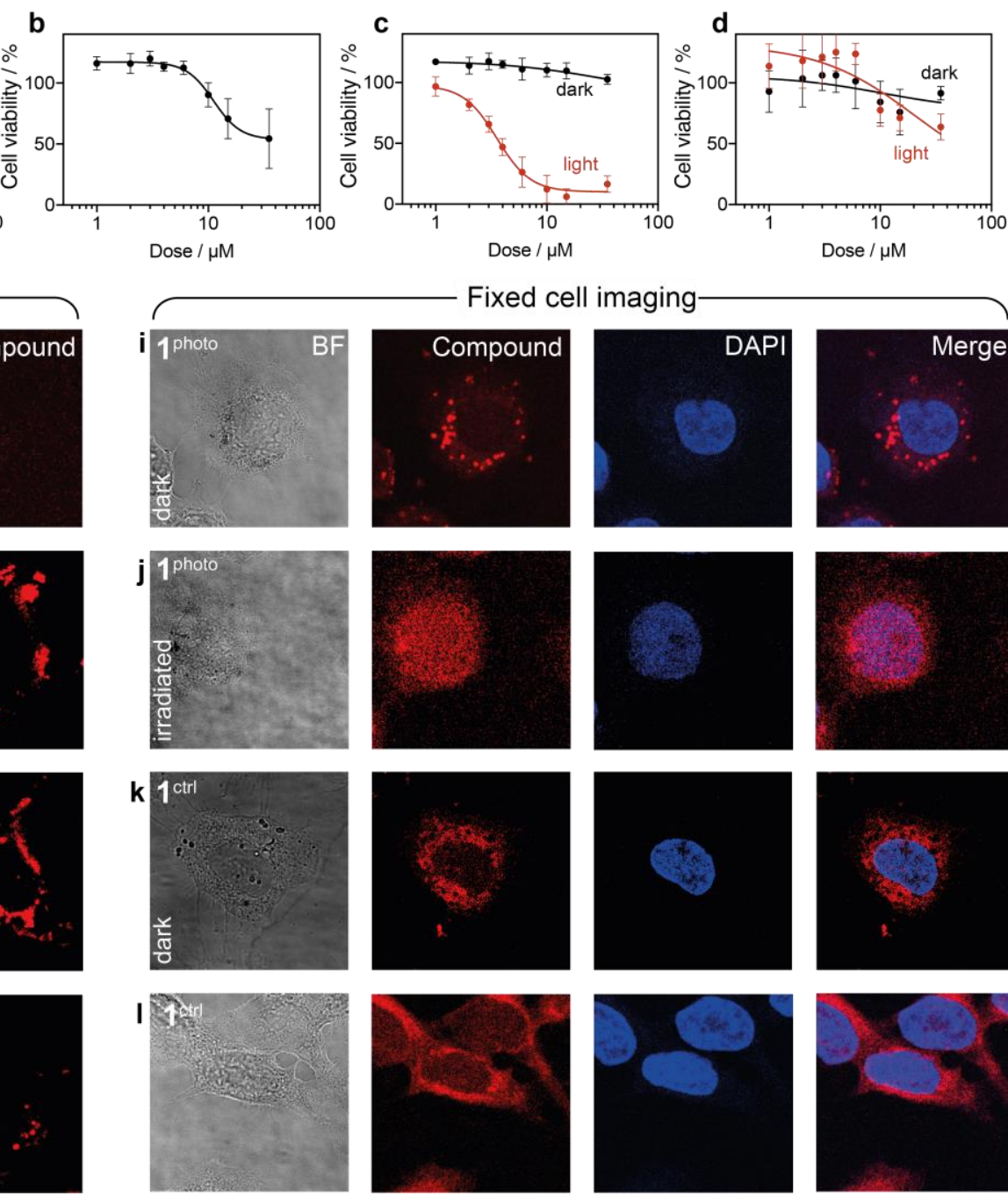
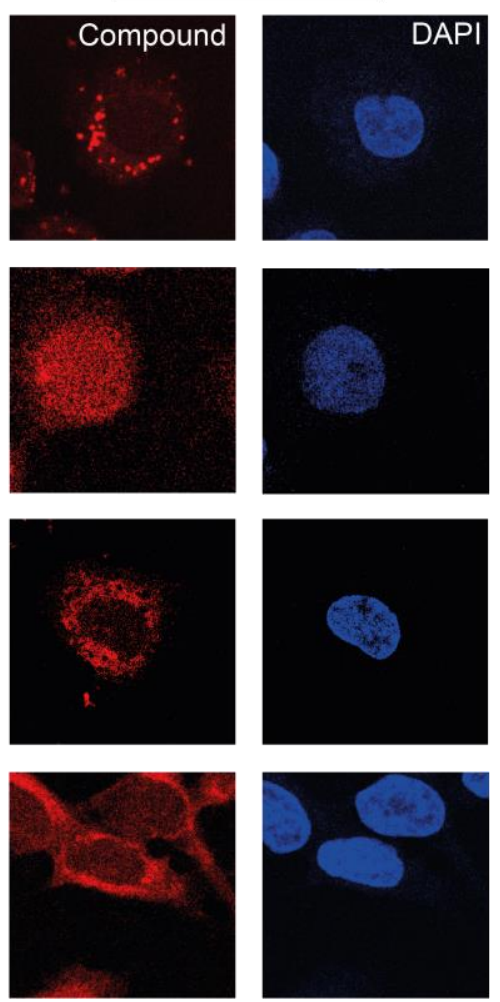
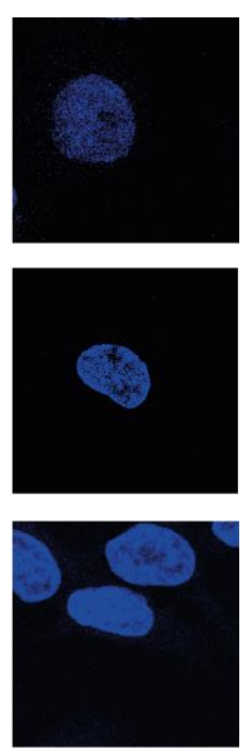
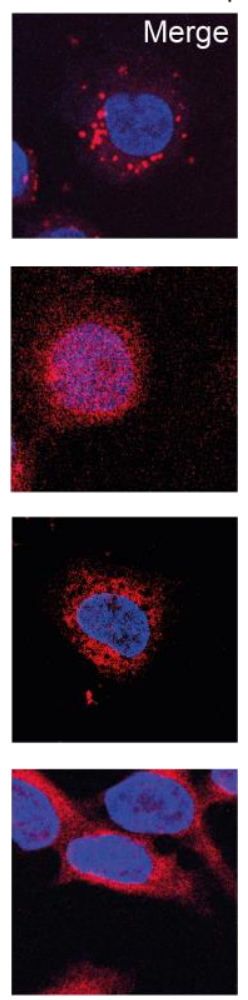

Figure 6 - Cell viability and localisation experiments. a-d) Cell viability assays with $\mathrm{Pt}$-salphen complex 2 and rotaxanes $1^{\text {enz }}, 1^{\text {photo }} \mathbf{1}^{\text {ctrl }}$ respectively. Cells were seeded and incubated for 24 hours, followed by compound addition. Cells were either incubated for a further 24 hour or irradiated at the 3 hour time point for 20 minutes using $365 \mathrm{~nm}$. e-h) Live cell fluorescence imaging experiments with with Pt"salphen complex 2 and rotaxanes $1^{\text {enz }}, 1^{\text {photo }}$ and $1^{\text {ctrl }}$ respectively. U2OS cells were seeded and incubated for 24 hours, followed by addition of the compounds $\left(2 \mu \mathrm{M}\right.$ for $1^{\text {enz }}$ and $1^{\text {photo }}, 10 \mu \mathrm{M}$ for $\left.1^{\text {trl }}\right)$ $\mathrm{Pt}^{\mathrm{H}}$-salphen $\lambda_{\mathrm{ex}}=458 \mathrm{~nm}, \lambda_{\mathrm{em}}=525-700 \mathrm{~nm}$. $\mathrm{f}-\mathrm{I}$ ), Fixed cell imaging experiments with rotaxanes $1^{\text {photo }}$ and 1 ctrl $(2 \mu \mathrm{M}$ for $24 \mathrm{~h})$ in cells which were either left in the dark or irradiated for 20 minutes at $365 \mathrm{~nm}$. DAPI was added for nuclear staining. Pt"-salphen $\lambda_{\mathrm{ex}}=458 \mathrm{~nm}, \lambda_{\mathrm{em}}=525-700 \mathrm{~nm}$, DAPI $\lambda_{\mathrm{ex}}=760 \mathrm{~nm}$ (2 photon), $\lambda_{e m}=400-450 \mathrm{~nm}$. All images are to the same scale.

We next set out to study the localisation of $1^{\text {photo }}$ in live cells upon UV-irradiation induced release. However, presumably due to the cytotoxic nature of the activated compound, there 
was significant cell death detected in the images upon irradiation, consistent with the cytotoxicity result discussed above (Figure 6c). Therefore, we carried out cellular experiments in which live cells were incubated for 24 hours with a non-cytotoxic dose of rotaxanes $1^{\text {photo }}$ and $\mathbf{1}^{\mathrm{ctrl}}$, after which the cells were washed and fixed with PFA. The cells were then either left in the dark or irradiated for 20 minutes at $365 \mathrm{~nm}$ before imaging (Figure 6f). The results for the cells kept in the dark corresponded well with the live cell imaging, again showing punctate staining for rotaxane $1^{\text {photo }}$ and a more general background staining for rotaxane $1^{\text {ctrl }}$, with littleto-no nuclear localisation in either case. However, upon irradiation, the staining pattern was completely transformed for rotaxane $\mathbf{1}^{\text {photo }}$ (see Figure 6j) showing primarily nuclear localisation, as evidenced by co-localisation with DAPI. This indicates that the probe interacts with nuclear DNA, although it is not possible to ascertain whether it selectively binds to G4 structures in cells (even if in vitro it shows good selectivity for G4s over duplex DNA). Importantly, no re-localisation was observed for the non-photocleavable control $1^{\text {ctrl }}$. Thus, the rotaxane cage facilitated cell uptake of $1^{\text {photo }}$ and the compound became toxic upon its release from the cage. Based on the data presented in Figure 6 we hypothesise that cytotoxicity arose from irradiation-induced relocalisation of $\mathrm{Pt}^{\prime \prime}$-salphen 2 to the nucleus and subsequent interaction with DNA.

\section{Conclusions}

In this study we have demonstrated that Pt"-salphen ligand which targets G4 DNA can be effectively caged through inclusion in a rotaxane. In vitro, DNA binding was entirely inhibited when the Pt"-salphen complex was part of the rotaxane. Upon removal of one of the stoppers from rotaxanes $\mathbf{1}^{\text {enz }}$ and $\mathbf{1}^{\text {phot }}$ by either an esterase or light irradiation respectively, we demonstrate that the DNA binding properties of the G4 ligand can be restored. While free $\mathrm{Pt}^{\prime \prime}-$ salphen is not taken up by live cells, good cell permeability was observed upon its inclusion in the rotaxanes. Finally, we have shown that photoactivation of $1^{\text {phot }}$ in cells, presumably leading to a release of the $\mathrm{Pt}^{\mathrm{H}}$-salphen complex, results in a high degree of spatiotemporal control of the cytotoxicity and cellular localisation of the G4 DNA binder. This approach by which a 
rotaxane is used to regulate the interaction between a small molecule and a biomolecular target, as well as to control its cellular uptake, localisation and cytoxicity, paves the way for the development of 'smart' drugs that can be carefully delivered and activated in a controlled fashion using external stimuli. These results demonstrate the viability of the mechanical bond to manipulate the physiochemical properties of therapeutics with precise temporal control. We envisage that this general strategy could be extended for controlled delivery and release of a range of drugs with various mechanisms of activation since our rotaxanes could be easily tailored to deliver a wide range of drugs to targeted locations as well as to explore other stimuli for the activation step.

\section{Acknowledgements}

The Engineering and Physical Sciences Research Council (EPSRC) of the UK is thanked for financial support including a studentship to T.K. and a fellowship for M.K.K (EP/I003983/1). Imperial College London is thanked for support for this project via the Excellence Fund for Frontier Research (P.A.S., M.K.K. and R.V.) and the Imperial College Research Fellowship program (J.E.M.L.). J.E.M.L. thanks Prof Matthew Fuchter for access to resources and useful discussions.

\section{Conflict of interest}

The authors declare no conflict of interest

\section{References}

[1] M. J. Langton, P. D. Beer, Acc. Chem. Res. 2014, 47, 1935-1949.

[2] S. Saha, J. F. Stoddart, Chem. Soc. Rev. 2007, 36, 77-92.

[3] C. J. Bruns, J. F. Stoddart, The Nature of the Mechanical Bond: From Molecules to Machines, 2016. 
[4] A. W. Heard, S. M. Goldup, ACS Cent. Sci. 2020, 6, 177-128.

[5] D. A. Leigh, V. Marcos, M. R. Wilson, ACS Catal. 2014, 4, 4490-4497.

[6] M. Denis, S. M. Goldup, Nat. Rev. Chem. 2017, 1, 1-18.

[7] M. S. Vickers, P. D. Beer, Chem. Soc. Rev. 2007, 36, 211-225.

[8] J. E. M. Lewis, P. D. Beer, S. J. Loeb, S. M. Goldup, Chem. Soc. Rev. 2017, 46, 2577-2591.

[9] J. E. Beves, B. A. Blight, C. J. Campbell, D. A. Leigh, R. T. McBurney, Angew. Chem. Int. Ed. 2011, 50, 9260-9327.

[10] A. Inthasot, S. T. Tung, S. H. Chiu, Acc. Chem. Res. 2018, 51, 1324-1337.

[11] J. D. Crowley, S. M. Goldup, A. L. Lee, D. A. Leigh, R. T. Mc Burney, Chem. Soc. Rev. 2009, 38, 1542-1550.

[12] J. P. Sauvage, Angew. Chem. Int. Ed. 2017, 56, 11080-11093.

[13] J. C. Chambron, J. P. Collin, V. Heitz, D. Jouvenot, J. M. Kern, P. Mobian, D. Pomeranc, J. P. Sauvage, Eur. J. Org. Chem. 2004, 8, 1627-1638.

[14] J. F. Stoddart, Angew. Chem. Int. Ed. 2017, 56, 11094-11125.

[15] N. Pairault, R. Barat, I. Tranoy-Opalinski, B. Renoux, M. Thomas, S. Papot, C. $R$. Chim. 2016, 19, 103-112.

[16] A. Harada, A. Hashidzume, H. Yamaguchi, Y. Takashima, Chem. Rev. 2009, 109, 5974-6023.

[17] F. Huang, H. W. Gibson, Prog. Polym. Sci. 2005, 30, 982-1018.

[18] J. Li, X. J. Loh, Adv. Drug Deliv. Rev. 2008, 60, 1000-1017.

[19] A. Tamura, N. Yui, Polym. J. 2017, 49, 527-534.

[20] M. W. Ambrogio, C. R. Thomas, Y. L. Zhao, J. I. Zink, J. F. Stoddart, Acc. Chem. Res. 2011, 44, 903-913.

[21] A. Fernandes, A. Viterisi, F. Coutrot, S. Potok, D. A. Leigh, V. Aucagne, S. Papot, Angew. Chem. Int. Ed. 2009, 48, 6443-6447.

[22] A. Fernandes, A. Viterisi, V. Aucagne, D. A. Leigh, S. Papot, Chem. Commun. 2012, 48, 2083-2085. 
[23] X. Wang, X. Bao, M. McFarland-Mancini, I. Isaacsohn, A. F. Drew, D. B. Smithrud, J. Am. Chem. Soc. 2007, 129, 7284-7293.

[24] X. Bao, I. Isaacsohn, A. F. Drew, D. B. Smithrud, J. Am. Chem. Soc. 2006, 128, $12229-12238$.

[25] J. J. Gassensmith, E. Arunkumar, L. Barr, J. M. Baumes, K. M. DiVittorio, J. R. Johnson, B. C. Noll, B. D. Smith, J. Am. Chem. Soc. 2007, 129, 15054-15059.

[26] R. Barat, T. Legigan, I. Tranoy-Opalinski, B. Renoux, E. Péraudeau, J. Clarhaut, P. Poinot, A. E. Fernandes, V. Aucagne, D. A. Leigh, S. Papot, Chem. Sci. 2015, 6, 2608-2613.

[27] A. Acevedo-Jake, A. T. Ball, M. Galli, M. Kukwikila, M. Denis, D. G. Singleton, A. Tavassoli, S. M. Goldup, J. Am. Chem. Soc. 2020, 142, 5985-5990.

[28] H. J. Lipps, D. Rhodes, Trends Cell Biol. 2009, 19, 414-422.

[29] J. Spiegel, S. Adhikari, S. Balasubramanian, Trends Chem. 2020, 2, 123-136.

[30] M. L. Bochman, K. Paeschke, V. A. Zakian, Nat. Rev. Genet. 2012, 13, 770-780.

[31] H. Han, L. H. Hurley, Trends Pharmacol. Sci. 2000, 21, 136-142.

[32] G. W. Collie, G. N. Parkinson, Chem. Soc. Rev. 2011, 40, 5867-5892.

[33] S. Neidle, Nat. Rev. Chem. 2017, 1, 1-10.

[34] S. Neidle, FEBS J. 2010, 277, 1118-1125.

[35] A. Bedrat, L. Lacroix, J. L. Mergny, Nucleic Acids Res. 2016, 44, 1746-1759.

[36] J. L. Huppert, S. Balasubramanian, Nucleic Acids Res. 2005, 33, 2908-2916.

[37] V. S. Chambers, G. Marsico, J. M. Boutell, M. di Antonio, G. P. Smith, S. Balasubramanian, Nat. Biotechnol. 2015, 33, 877-881.

[38] R. Hänsel-Hertsch, D. Beraldi, S. v. Lensing, G. Marsico, K. Zyner, A. Parry, M. di Antonio, J. Pike, H. Kimura, M. Narita, D. Tannahill, S. Balasubramanian, Nat. Genet. 2016, 48, 1267-1272.

[39] G. Biffi, D. Tannahill, J. McCafferty, S. Balasubramanian, Nat. Chem. 2013, 5, 182186. 
[40] G. Biffi, D. Tannahill, J. Miller, W. J. Howat, S. Balasubramanian, PLOS ONE 2014, 9, e102711.

[41] M. di Antonio, A. Ponjavic, A. Radzevičius, R. T. Ranasinghe, M. Catalano, X. Zhang, J. Shen, L. M. Needham, S. F. Lee, D. Klenerman, S. Balasubramanian, Nat. Chem. 2020, 12, 832-837.

[42] A. Shivalingam, M. A. Izquierdo, A. le Marois, A. Vyšniauskas, K. Suhling, M. K. Kuimova, R. Vilar, Nat. Commun. 2015, 6, 832-837.

[43] M. P. O’Hagan, S. Haldar, M. Duchi, T. A. A. Oliver, A. J. Mulholland, J. C. Morales, M. C. Galan, Angew. Chem. Int. Ed. 2019, 58, 4334-4338.

[44] P. Murat, M. v. Gormally, D. Sanders, M. di Antonio, S. Balasubramanian, Chem. Commun. 2013, 49, 8453-8455.

[45] T. Nakamura, K. lida, M. Tera, K. Shin-ya, H. Seimiya, K. Nagasawa, ChemBioChem 2012, 13, 774-777.

[46] S. Bandeira, J. Gonzalez-Garcia, E. Pensa, T. Albrecht, R. Vilar, Angew. Chem. Int. Ed. 2018, 57, 310-313.

[47] N. H. Abd Karim, O. Mendoza, A. Shivalingam, A. J. Thompson, S. Ghosh, M. K. Kuimova, R. Vilar, RSC Adv. 2014, 4, 3355-3363.

[48] N. H. Campbell, N. H. A. Karim, G. N. Parkinson, M. Gunaratnam, V. Petrucci, A. K. Todd, R. Vilar, S. Neidle, J. Med. Chem. 2012, 55, 209-222.

[49] V. Aucagne, K. D. Hänni, D. A. Leigh, P. J. Lusby, D. B. Walker, J. Am. Chem. Soc. 2006, 128, 2816-2817.

[50] V. Aucagne, J. Berná, J. D. Crowley, S. M. Goldup, K. D. Hänni, D. A. Leigh, P. J. Lusby, V. E. Ronaldson, A. M. Z. Slawin, A. Viterisi, D. B. Walker, J. Am. Chem. Soc. 2007, 129, 11950-11963.

[51] H. Lahlali, K. Jobe, M. Watkinson, S. M. Goldup, Angew. Chem. Int. Ed. 2011, 50, 4237-4241.

[52] J. E. M. Lewis, R. J. Bordoli, M. Denis, C. J. Fletcher, M. Galli, E. A. Neal, E. M. Rochette, S. M. Goldup, Chem. Sci. 2016, 7, 3154-3161. 
Text and Figure for Table of Contents

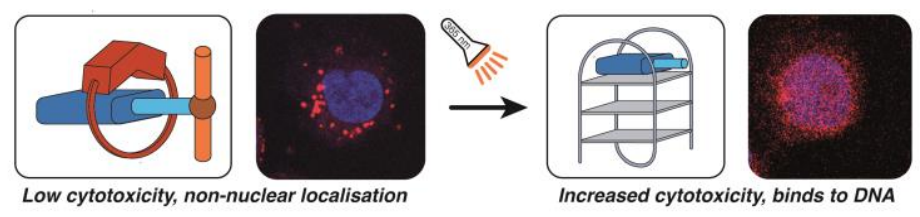

The efficacy of many drugs can be limited by undesirable properties including low bioavailability and 'off-target' interactions. Herein we demonstrate the potential for using mechanical protection to 'cage' a DNA-targeting metallodrug within a photodegradable rotaxane, leading to enhanced cell permeability and limited cytotoxicity in cancer cells. Light activation leads to a dramatic increase in cytotoxicity and translocation to the cell nucleus. 